\title{
CATALOGAÇÃO DESCRITIVA E TEMÁTICA DE DOCUMENTOS MUSICAIS NO CONTEXTO DA BIBLIOTECA UNIVERSITÁRIA
}

\author{
Diego Rodrigues Figueiredo \\ Graduado em Biblioteconomia e Documentação. \\ Universidade Federal Fluminense, Niterói \\ Rio de Janeiro, Brasil. \\ diegobbliotheconomie@gmail.com \\ https://orcid.org/0000-0003-1415-1064
}

\author{
Joice Cleide Cardoso Ennes de Souza \\ Doutora em Ciência da Informação. Universidade Federal \\ Fluminense, Niterói, Rio de Janeiro, Brasil. \\ joicecardoso@id.uff.br \\ https://orcid.org/0000-0002-3848-4923
}

Elisabete Gonçalves de Souza

Doutora em História e Filosofia da Educação Brasileira.Universidade Federal Fluminense, Niterói, Rio de

Janeiro, Brasil.

elisabetegs@id.uff.br

https://orcid.org/0000-0001-9707-6017

\begin{abstract}
RESUMO
Objetiva analisar a catalogação descritiva e temática do documento musical, mais especificamente partitura, no âmbito da biblioteca universitária, de forma a discutir os aspectos relevantes a serem considerado no tratamento informacional desse recurso. Pesquisa de natureza básica, com abordagem qualitativa, bibliográfica e descritiva. A partir da análise da partitura musical de piano "Dansa Brasileira" de Camargo Guarnieri, depositada na Biblioteca Setorial do Centro de Letras e Artes da UNIRIO, destacou-se os aspectos adotados no tratamento informacional do documento à luz da literatura da área. Conclui-se que, para o tratamento informacional de um documento musical, é necessário que o catalogador desenvolva competência informacional de forma a conhecer as particularidades do documento e explorar o seu potencial informacional.
\end{abstract}

Palavras-chave: Catalogação descritiva. Catalogação temática. Biblioteca universitária. Documento musical.

\section{DESCRIPTIVE AND THEMATIC CATALOGINGOF MUSICAL DOCUMENTS IN THE CONTEXT OF THE UNIVERSITY LIBRARY}

\begin{abstract}
The research aims to analyze the descriptive and thematic cataloging of musical documents, more specifically musical scores, in the scope of university libraries, in order to study the aspects considered in the cataloging. The researchis of basic nature, with qualitative, bibliographic and descriptive approach. It has analyzed the piano sheet music of "Dansa Brasileira" by Camargo Guarnieri, deposited in the Biblioteca Setorial do Centro de Letras e Artes of UNIRIO. The aspects adopted in the informational treatment of the document were highlighted on the basis of the literature of the area. The research has concluded that, for the informational treatment of musical documents, it is necessary for the cataloger to develop informational competence in order to know the particularities of the document and to explore its informational potential.
\end{abstract}

Keywords: Descriptive cataloging. Thematic cataloging. University library. Musical document. 


\section{INTRODUÇÃO}

O ato de ouvir e interagir com a música é comum a maioria das pessoas, porém, são poucos os que detêm conhecimento sobre os estudos musicais. A música é uma área de conhecimento abrangente, com características e linguagem própria. A notação musical estabelece relações com outros campos do conhecimento, como a matemática, artes, pedagogia, psicologia, física, etc. A música pode ser entendida como uma arte que utiliza a combinação dos sons de forma ordenada, com a finalidade de criar uma obra passível de ser representada através de uma linguagem, capaz de ser decodificada e seu conteúdo reproduzido.

A música produz informações resultantes das pesquisas e das obras musicais produzidas pelos músicos. Essas informações, denominadas por alguns autores como informação musical, serão registradas em um suporte físico, o que resultará no documento musical.

Devido à particularidade do documento musical e de seu tratamento informacional, apresentamos as seguintes questões: Quais entidades e atributos devem ser considerados na representação descritiva de um documento musical no âmbito da biblioteca universitária? Quais procedimentos observarem termos de normas e padrões para garantir a consistência dos dados e a recuperação das informações?

Diante do problema, objetiva-se identificar os critérios a serem adotados para representar um documento como musical, de forma a definir os elementos descritivos a serem considerados no seu tratamento informacional, no âmbito da biblioteca universitária.

Ao proporcionar uma análise sobre as peculiaridades do documento musical no âmbito da biblioteca universitária, possibilitamos um conhecimento sobre este gênero documental, colaborando com a tomada de decisão do catalogador em relação às técnicas a serem utilizadas no tratamento informacional.

No tocante aos procedimentos metodológicos, realizamos levantamento bibliográfico sobre música e tratamento informacional em catálogos de bibliotecas universitárias e em sites de instituições com acervo musical (USP, Biblioteca Nacional e UNIRIO). Consultamos também as bases BRAPCI ${ }^{1}, \mathrm{BENANCIB}^{2}, \mathrm{BDTD}^{3}$ na busca

\footnotetext{
${ }^{1}$ Base de Dados em Ciência da Informação

${ }^{2}$ Repositório das comunicações realizadas no Encontro Nacional de Pesquisa (ENANCIB) em Ciência da Informação, realizado anualmente pela Associação Nacional de Pesquisa e Pós-Graduação em Ciência da Informação (ANCIB)
} 
por monografias, dissertações, teses, obras de referência e artigos de periódicos científicos que destacavam o tema proposto.

Como marco empírico, analisamos os aspectos aplicados no tratamento informacional de uma partitura musical na Biblioteca Setorial do Centro de Letras e Artes da UNIRIO (BSCLA), selecionada por ser uma biblioteca universitária com acervo de música. Desta forma, foi possível analisar os aspectos utilizados pela instituição com aqueles recomendados pelas áreas de catalogação descritiva e temática.

Após essa introdução, apresentaremos o conceito de documento musical e suas principais características, para depois destacarmos o tratamento informacional desse tipo de recurso. O lócus de nossa pesquisa será detalhado na seção 4, quando nos deteremos na Biblioteca Setorial do Centro de Letras e Artes da UNIRIO (BSCLA), e na análise do tratamento informacional recebido pela partitura musical " dansa Brasileira". Em seguida, na discussão, fazemos uma comparação entre o tratamento informacional dado ao documento pela BSCLA e por outra duas bibliotecas: a Biblioteca Nacional do Brasil (BN) e a Library of Congress (LC). As duas bibliotecas citadas foram escolhidas para análise comparativa pelos seguintes motivos: a BN é a entidade catalogadora nacional e a LC é uma das maiores bibliotecas do mundo, referência internacional para a área de catalogação descritiva. Na seção 5 apresentamos nossa conclusão seguida pelas referências citadas.

\section{DOCUMENTO MUSICAL}

Para que um conteúdo informacional seja acessado, é necessário que esteja registrado em um suporte capaz de armazená-lo. Dessa forma, independente de seu formato, temos um documento. Documento não possui um conceito único dada sua múltipla dimensão nas áreas da Arquivologia, da Biblioteconomia e da Museologia. O conceito do que venha ser um documento varia de acordo com o contexto no qual se insere. No âmbito deste artigo, adotaremos a definição da norma NBR 6023 da Associação Brasileira de Normas Técnicas (2018, p.2), por melhor compreender a ideia de documento em bibliotecas, ao defini-lo como "qualquer suporte que contenha informação registrada, formando uma unidade, que possa servir para consulta, estudo ou prova. Inclui impressos, manuscritos, registros audiovisuais, sonoros, magnéticos e eletrônicos, entre outros".

\footnotetext{
${ }^{3}$ Biblioteca Digital Brasileira de Teses e Dissertações
} 
Segundo Blanco (2016, p.78), documento musical é o documento "em que a música predomina em alguma das suas dimensões (fenomenológica - sonora ou audiovisual, ou semiológica - notacional musical)". Nesse sentido, a informação musical está codificada na notação musical. Conforme destaca Barros (2012, p.50), para que uma informação seja considerada musical deve apresentar em seu conteúdo elementos musicais como: notações; melodia; ritmo; harmonia; contraponto; altura; duração; intensidade; timbre.

Segundo Matos (2007), o documento musical pode apresentar-se nas formas escrita, sonora e audiovisual. Documento musical textual é todo aquele representado por uma linguagem escrita, podendo ser através das notações musicais. A partitura é um exemplo de documento musical textual, definida como toda "forma de música escrita ou impressa que abriga todo um conjunto de elementos da notação musical, de maneira a representar visualmente a coordenação musical, garantindo com maior ou menor precisão a sua execução" (SADIE, 1994, p.702). A norma NBR 6023 da Associação Brasileira de Normas Técnicas (2018) aponta que as partituras podem apresentar-se em meio impresso ou eletrônico, tendo como suporte qualquer meio capaz de armazenar esse tipo de formato.

De acordo com o Glossário da AACR2r (2002), há oito tipos de partituras com diferentes formatos de publicação, sendo sua escolha dependente do tipo da obra musical e da forma de execução. No Quadro 1 consolidamos os tipos de partituras e suas definições.

Quadro 1 - Tipos de partituras musicais

\begin{tabular}{|c|l|}
\hline $\begin{array}{c}\text { TIPO DE PARTITURA } \\
\text { Partitura completa ou } \\
\text { partitura de regência }\end{array}$ & $\begin{array}{l}\text { Partitura para orquestra contendo detalhes completos de uma obra, } \\
\text { tal como se pretende que ela seja executada (SADIE, 1994). }\end{array}$ \\
\hline Partitura condensada & $\begin{array}{l}\text { Partitura musical que registra somente as partes principais da } \\
\text { música em um número reduzido de pautas e organizado } \\
\text { geralmente por seções instrumentais (AACR2r, 2002). }\end{array}$ \\
\hline Partitura de bolso & $\begin{array}{l}\text { Partitura musical não destinada, a princípio, para ser executada, } \\
\text { com notação e/ou texto em formato reduzido (AACR2r, 2002). }\end{array}$ \\
\hline Partitura de coro & $\begin{array}{l}\text { Partitura de obra para canto, que mostra somente as partes do } \\
\text { coro, com acompanhamento, se houver, com arranjo para } \\
\text { instrumento de teclado (AACR2r, 2002). }\end{array}$ \\
\hline $\begin{array}{l}\text { Partitura de piano ou } \\
\text { "redução para piano" }\end{array}$ & $\begin{array}{l}\text { Expressão usada para o arranjo (em geral para piano) de música } \\
\text { escrita originalmente para orquestra ou outros conjuntos. Uma } \\
\text { forma específica muito utilizada é a da "partitura para canto ou } \\
\text { piano", em que o acompanhamento instrumental para uma ou } \\
\text { mais vozes é reduzido para a execução ao piano. (SADIE, 1994). }\end{array}$ \\
\hline
\end{tabular}


Continuação

\begin{tabular}{|c|l|}
\hline TIPO DE PARTITURA & \multicolumn{1}{|c|}{ DEFINIÇÃO } \\
\hline Partitura fechada & $\begin{array}{l}\text { Partitura de música, que registra todas as partes em um } \\
\text { número mínimo de pautas, geralmente duas, como nos hinos } \\
\text { (AACR2r, 2002). }\end{array}$ \\
\hline Partitura incompleta & $\begin{array}{l}\text { Esboço feito por um compositor para uma obra destinada a um } \\
\text { conjunto, ressaltando em poucas pautas as características } \\
\text { principais da composição (AACR2r, 2002). }\end{array}$ \\
\hline Partitura vocal & $\begin{array}{l}\text { Partitura que apresenta todas as partes vocais, com o } \\
\text { acompanhamento, se houver, com arranjo para instrumento de } \\
\text { teclado (AACR2r, 2002). }\end{array}$ \\
\hline
\end{tabular}

Fonte: elaborado pelos autores (2020)

Nosso trabalho focará na representação da partitura de piano "Dansa Brasileira". O documento musical textual também pode se apresentar de forma híbrida, contendo informação representada em linguagem natural e em notações musicais (cifras, tablaturas, partituras). Podemos citar como exemplo os livros que retratam a história da música, dicionários especializados de música, livros didáticos do ensino de música, songbooks, etc. Já o documento musical sonoro apresenta seu conteúdo informacional musical somente em som, enquanto os documentos musicais audiovisuais aliam o som à imagem, estática ou em movimento, na transmissão de sua mensagem (ARQUIVO NACIONAL, 2005).

No âmbito biblioteconômico, Blanco (2016, p.75) divide a documentação musical em dois conjuntos: "documentos musicais bibliográficos" e "documentos musicais não bibliográficos". Os "documentos musicais bibliográficos" compreendem o conjunto de documentos musicais em formato impresso, como a partitura. Já os "documentos musicais não bibliográficos" são os documentos musicais em formato audiovisual, sonoro, etc.

A partir de uma abordagem arquivística, Blanco (2016, p.78) considera o gênero "documentação relativa à música" como o conjunto de documentos em que a informação musical se apresenta em qualquer um dos seus aspectos e graus de relação com a música. Para o autor, esse gênero compreende uma família documental denominada "documentos musicais". Nessa família documental, Blanco (2016, p.78-79) destaca o conjunto de documentos de dimensão informacional semiótica codificada em notações, denominado por "documentos musicográficos". Nesse sentido, os "documentos musicográficos" podem ser entendidos como aqueles que carregam informação essencialmente musical, sendo representado pelas notações musicais. Partituras, cilindros, discos, rolos, entre outros, são exemplos de documentos musicográficos. 
Diante da proposta conceitual de Blanco (2016, p.81), partitura é um:

Documento musicográfico que contém a representação escrita em notação musical (ou equivalente) de todos os detalhes necessários aos diversos meios (instrumentais e/ou vocais, geralmente dispostos em pautas superpostas) para que, quando lidos simultaneamente, resultem na realização completa da peça musical nela registrada. Esta espécie inclui tipos como o Arranjo, a Redução e o Excerto.

Os documentos musicais possuem as seguintes especificidades: linguagem específica, como as notações musicais (partituras, cifras, tablaturas, etc.); metadados específicos da área musical (tipo de partitura, instrumento, voz, gênero, etc.) e tipologias documentais inerentes a esse tipo de documento (partitura condensada, partitura de piano, etc.). Dentro dessa perspectiva, Blanco (2016, p.77) ressalta que o não reconhecimento desses documentos como musicais, assim como seu tratamento inadequado, pode gerar a perda da identidade ontológica do documento, do valor informacional e do controle no fluxo, como consulta, empréstimo e devolução.

\section{TRATAMENTO INFORMACIONAL DE DOCUMENTOS MUSICAIS}

Para que os usuários de uma biblioteca acessem os documentos que compõem seu acervo é necessário que eles estejam devidamente organizados e representados através do tratamento informacional, processo que envolve a descrição catalográfica e temática da obra, visando à identificação de seus dados bibliográficos e de conteúdo, fundamentais na organização, armazenamento e acesso.

Mey e Silveira (2009, p.7) nos oferecem uma visão abrangente do processo de catalogação ao afirmar que é:

O estudo, preparação e organização de mensagens, com base em registros do conhecimento, reais ou ciberespaciais, existentes ou passíveis de inclusão em um ou vários acervos, de forma a permitir a interseção entre as mensagens contidas nestes registros do conhecimento e as mensagens internas dos usuários (MEY; SILVEIRA, 2009, p.7).

Já para Dias e Naves (2013, p.IX), o tratamento da informação:

[...] tem sido considerado [como] uma das funções de grande importância no desempenho de bibliotecas e sistemas de recuperação da informação. Pode ser dividido em dois grandes tipos, de acordo com a natureza da atividade que desenvolve: o tratamento descritivo, que lida com dados objetivos extraídos do documento, e o tratamento temático, que procura descrever o conteúdo (o "assunto") do documento. 
Conforme apontam Dias e Naves (2013), no tratamento temático é analisado o conteúdo do documento com o objetivo de determinar, e posteriormente extrair, o assunto contido no mesmo, representando seu conteúdo intelectual. Já no tratamento descritivo destacam-se os atributos físicos ou objetivos do documento.

O processo de análise é o primeiro passo para representar o documento. Dias e Naves (2013, p.IX) denominam esse processo como análise de assunto, e afirmam que "[...] é o processo de ler um documento para extrair conceitos que traduzam a essência de seu conteúdo".

Para dar início ao tratamento informacional do documento, o catalogador procede a leitura documentária. Segundo Fujita e Rubi (2006, p.1), "o indexador é um leitor que interage com o texto para cumprir o objetivo da indexação. Nessa interação, o indexador lê o texto". Complementam Dias e Naves (2013, p.43) afirmando que "a leitura técnica tornou-se, assim, a estratégia clássica de leitura para análise de assunto". Apesar de ser aplicada prioritariamente a livros, a leitura documentária pode ser estendida para outros formatos de documentos, como o documento musical.

Segundo Lancaster (2004, p.6), na indexação "os termos atribuídos pelo indexador servem como pontos de acesso mediante os quais um item é localizado e recuperado, durante uma busca por assunto num índice publicado ou numa base de dados eletrônica".

O documento UNISIST (1981, p.84) esclarece que indexação "é vista como a ação de descrever e identificar um documento de acordo com seu assunto", e compreende três etapas: compreensão do conteúdo do documento; identificação e seleção dos conceitos. As recomendações do UNISIST deram origem à Norma ISO 5693 que, por sua vez, foi traduzida em português com a denominação NBR 12676/1992. A norma brasileira define indexação como o "Ato de identificar e descrever o conteúdo de um documento com termos representativos dos seus assuntos e que constituem uma linguagem de indexação" (ASSOCIAÇÃO BRASILEIRA DE NORMAS TÉCNICAS, 1992, p.2) e a divide em três estágios: análise do documento; identificação dos conceitos e seleção de termos de indexação.

$\mathrm{Na}$ etapa sobre a análise do documento, a Norma NBR 12676 da Associação Brasileira de Normas Técnicas (1992, p.2) nos orienta a observar o tipo de documento e prevê a utilização dos termos documentos impressos e documentos não impressos. O UNISIT os denomina documentos gráficos e não gráficos, respectivamente. 
Para analisar um documento impresso a Norma NBR 12676 da Associação Brasileira de Normas Técnicas (1992, p.2), recomenda observar: o título e subtítulo; resumo, se houver; sumário, introdução; ilustrações, diagramas, tabelas e seus títulos explicativos; palavras ou grupos de palavras em destaque (sublinhadas, impressas em tipo diferente, etc); e as referências. No caso dos documentos não impressos, como audiovisuais, visuais e sonoros, a norma recomenda analisar o documento a partir do título ou da sinopse, destacando ser necessário ter acesso ao documento na íntegra, caso esses recursos pareçam inadequados.

$\mathrm{Na}$ etapa da seleção de conceitos, contamos com instrumentos de controle terminológico, como tesauros e vocabulários controlados, que são linguagens artificiais usadas na indexação, armazenamento e recuperação dentro de um dado sistema de informação. No âmbito dos documentos musicais não foram identificadas linguagens específicas para a música, com exceção do vocabulário controlado do SIBi/USP. Observamos a pesquisa de Souza (2008), que apresenta uma sugestão de um microtesauro em música e o trabalho de Cardoso (1996), que estabelece uma estrutura básica de um vocabulário controlado para indexação de partituras.

Apesar de Lancaster (2004, p.21) problematizar a utilização do termo classificação, entendendo-o de forma mais abrangente de modo a compreender todas as atividades de organização da informação, para Barbosa (1969, p.17), "o processo de classificar livros implica, portanto, em agrupá-los por assuntos de que tratam, trocando o nome ou o termo dos mesmos por sinais ou símbolos correspondentes". Nesse sentido, classificação, no âmbito das bibliotecas, é o processo pelo qual o conteúdo temático de um livro será analisado através da análise de assunto e posteriormente classificado de acordo com seu assunto, sendo representado por uma notação, obtida através de uma linguagem notacional, como os sistemas de classificação bibliográfica (Classificação Decimal de Dewey - CDD ou Classificação Decimal Universal - CDU).

Paralelamente à indexação, procede-se o tratamento descritivo.Sobre a Representação Descritiva, Silveira (2019, p.180) a define como "a etapa do tratamento documental responsável pela descrição bibliográfica que identifica e individualiza um documento", estabelecendo os seus pontos de acesso e descrevendo outros elementos que possibilitam sua recuperação e acesso, como o título e responsabilidades.

Os elementos descritivos são estabelecidos pela Internacional Standard Bibliographic Description (ISBD). A finalidade da norma é a promoção do controle bibliográfico universal, 
fornecendo para isso uma estrutura de metadados internacionalmente aceita para a descrição da informação bibliográfica de todos os recursos publicados. Conforme a ISBD (IFLA, 2011), a descrição bibliográfica deve ser feita observando-se as seguintes áreas: (0) Forma do conteúdo e tipo de mídia (Content form and mediatype); (1) Título e responsabilidade (Title and statement of responsibility); (2) Edição (Edition); (3) Detalhes específicos do material (Material or type of resource specific); (4) Publicação, distribuição etc. (Publication, production, distribution, etc.); (5) Descrição física (Material description); (6) Série (Series and multipart monographic resource); (7) Notas (Notes); (8) Número internacional normalizado ((Resource identifier and terms of availability).

Para auxiliar nesse processo utiliza-se o Código de Catalogação Anglo-Americano, segunda edição revista (AACR2r, 2002), que objetiva padronizar a descrição bibliográfica. Nos capítulos 5 e 6 do AACR2r, são apresentadas as diretrizes para catalogar obras musicais.

O capítulo 5 (AACR2r, 2002) discorre sobre a descrição de música impressa publicada. A norma, porém, não especifica a descrição de documentos musicais escritos híbridos, como os songbooks, contemplando somente documentos musicais escritos, contendo notação musical, como as partituras. Os principais elementos de descrição apontados no capítulo são: área do título e indicação de responsabilidade; área da edição; área da indicação de apresentação musical; área da publicação, distribuição, etc.; indicação da descrição física; área da série, área das notas; área do número normalizado e das modalidades de aquisição.

Já a música gravada, ou documentos musicais sonoros, é tratada no capítulo 6 (AACR2r, 2002). Independente do suporte, os principais elementos de descrição são: área do título e indicação de responsabilidade; área da edição; área da indicação de apresentação musical; área da publicação, distribuição, etc.; indicação da descrição física; área da série, área das notas; área do número normalizado e das modalidades de aquisição.

No cenário das tecnologias da informação e comunicação, observamos o formato MARC 21 (Machine Readable Cataloging), que tem como objetivo organizar a entrada de dados nos catálogos eletrônicos. Assim, propomos uma análise da representação descritiva da partitura "Dansa Brasileira" adotando como referencial as diretrizes do AACR2r e os procedimentos de entrada de dados MARC 21, uma vez que os referidos padrões podem ser aplicados a qualquer tipo de documento. Conforme Serra et al. 
(2017, p.59), o formato tem como filosofia "[...] ser capaz de armazenar informação de todos os tipos de materiais em tags, indicadores e subcampos" explicitando os recursos e seus elementos e dados, tais como autor, título, edição, etc.

A importância do formato está na promoção do intercâmbio de registros bibliográficos, instaurando serviços de catalogação cooperativa, o que permite o uso e o reuso das informações por parte dos catalogadores, economizando o tempo e os custos do trabalho. Mas os registros intercambiados não podem ser considerados prontos, eles precisam ser revistos visando atender as necessidades dos usuários de cada unidade de informação, por isso ajustes de elementos descritivos são necessários durante o processo de criação de registros, o que exige esforço do catalogador "para a adequação, o preenchimento de novos dados ou a alteração dos existentes (SERRA et al., 2017, p.57). No que diz respeito ao nível de descrição, pode-se optar por uma descrição simples ou exaustiva, isso vai depender da política de catalogação adotada pela instituição.

\section{DOCUMENTOS MUSICAIS DA BIBLIOTECA SETORIAL DO CENTRO DE LETRAS E} ARTES DA UNIRIO

A Biblioteca Pernambuco de Oliveira, também conhecida como Biblioteca Setorial do Centro de Letras e Artes (BSCLA) é uma biblioteca universitária, integrante do Sistema de Bibliotecas da UNIRIO (UNIBIBLI), criado em 1986. A biblioteca atende aos docentes e discentes do Instituto Villa-Lobos, que faz parte do Centro de Letras e Artes (CLA), que oferece cursos de bacharelado em Canto, Composição, Instrumentos, Regência, Música Popular Brasileira, Arranjo Musical e licenciatura em música. Na pós-graduação dispõe do curso de mestrado profissional em práticas musicais e do mestrado e doutorado acadêmicos em música.

Biblioteca universitária, segundo Cunha e Cavalcanti (2008, p.53), é aquela "[...] mantida por uma instituição de ensino superior e que atende às necessidades de informação dos corpos docente, discente e administrativo, tanto para apoiar as atividades de ensino, quanto de pesquisa e extensão". Ou seja, uma biblioteca universitária com acervo de música terá como finalidade servir de apoio ao ensino, à pesquisa e à extensão universitária dos cursos de graduação e pós-graduação em música oferecidas pela universidade. 
A BSCLA coloca à disposição dos seus usuários o banco de peças teatrais e o banco de partituras musicais. O banco de partituras pode ser acessado fisicamente ou online, e foi herdado do Conservatório Nacional, possibilitando pesquisas históricas, pesquisas de tipografia musical, pesquisa de música em geral, entre outras. $\mathrm{O}$ acervo da biblioteca é diversificado, composto por documentos sonoros, textuais e audiovisuais. Oferecem ao usuário livros, teses, dissertações, periódicos, CDs, DVDs, vinis, partituras, etc. A coleção de vinil conta com 8.000 itens ainda não tratados. O banco de partituras é composto por 6.750 itens em tratamento informacional.

\subsection{Apresentação e análise da partitura Dansa Brasileira}

Devido à partitura ser o documento musical mais buscado pelos usuários na BSCLA, selecionamos para análise a partitura "Dansa Brasileira" de Camargo Guarnieri (ver Figura 1), parte integrante da coleção especial da professora Vera Janacópulos, e componente do banco de partituras.

A obra consiste em uma partitura de piano que se caracteriza pelas partes vocais constarem na íntegra. Conforme sinalizado na Figura 1, outra característica importante para reconhecer uma partitura de piano é a utilização das claves de sol e de fá, pois nesse tipo de partitura essas claves são executadas ao mesmo tempo. As claves são símbolos colocados no início de cada pauta (conjunto de 5 linhas e 4 espaços), antes do marcador de compasso, símbolo em formato de fração. Para identificar se as claves de sol e fá serão executadas ao mesmo tempo, basta verificar um símbolo em forma de colchete, antes das claves, ligando duas pautas. Essas informações são importantes para a representação documental de partituras e podem ser incluídas na área de notas do registro bibliográfico, assim o usuário saberá como proceder na execução desta peça musical, o que Ihe auxiliará na decisão sobre a escolha do item. 
Figura 1 - Partitura de piano da obra Dansa Brasileira

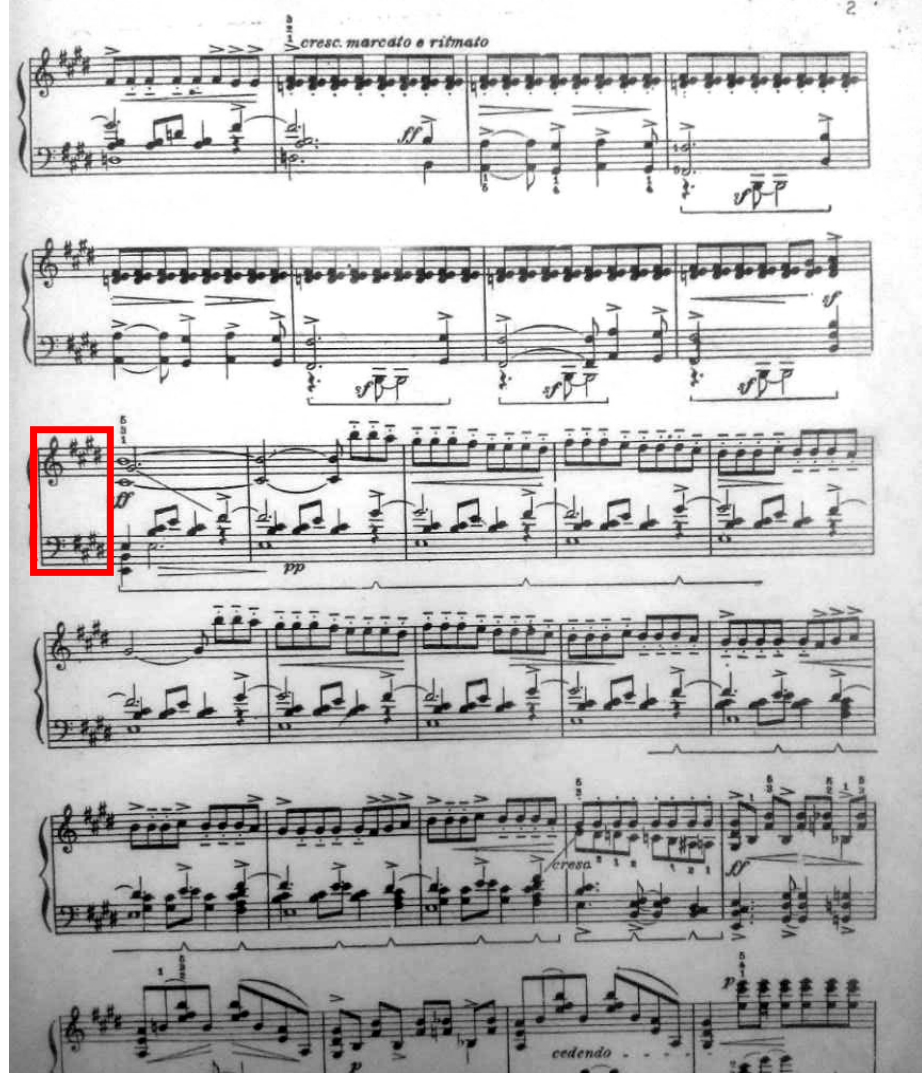

Fonte: Guarnieri (1948, p.2)

Com base na Figura 2, procedemos a análise em relação ao tratamento informacional. Observou-se que a partitura "Dansa Brasileira" foi catalogada, sendo descritos os elementos bibliográficos e temáticos básicos para representá-la para fins de organização e recuperação após ser depositada no acervo.

Figura 2 - Descrição da partitura Dansa Brasileira no catálogo online do sistema de bibliotecas da UNIRIO - Interface do usuário

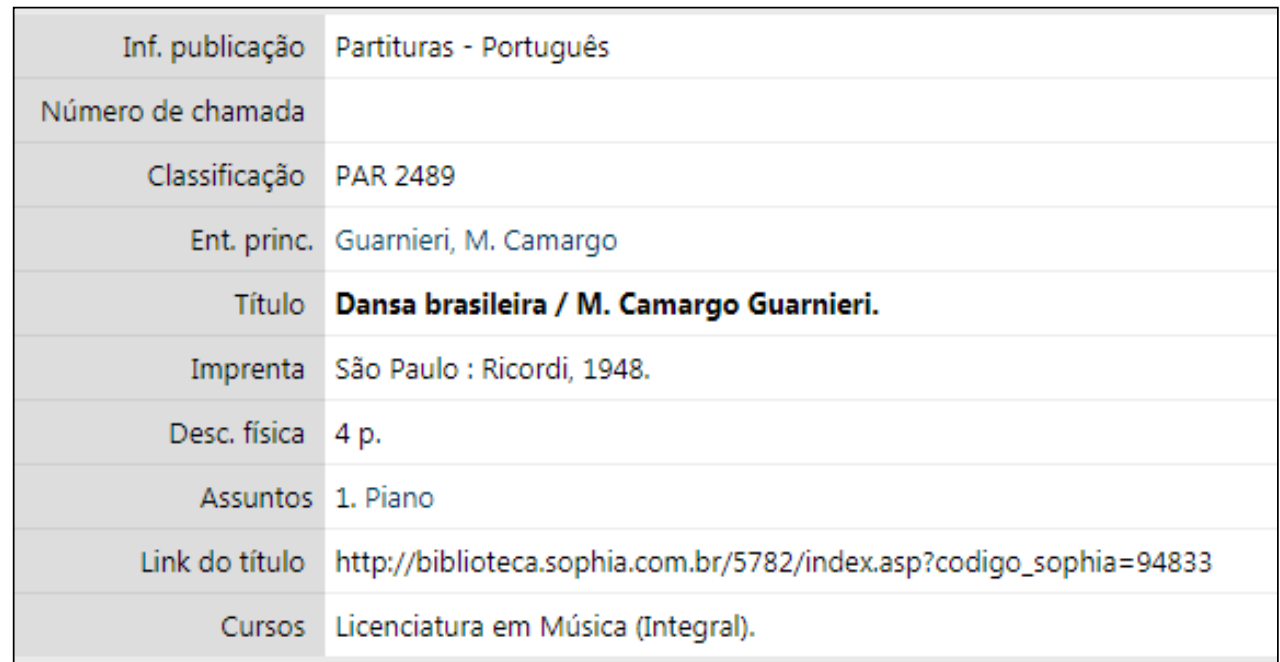

Fonte: UNIRIO (2019) 
A Figura 2 mostra o template do registro documentário em sua interface com o usuário. No que concerne à catalogação descritiva, foram descritos os elementos principais da partitura "Dansa Brasileira" de modo que possa ser recuperada por meio de acesso remoto. Observamos que os elementos descritivos estão em conformidade com as diretrizes do Capítulo 5 do AACR2r (música publicada) são eles: título da obra; autor; publicação; data de publicação e descrição física e tipo de documento. A catalogação temática é sucinta sendo indicado apenas um assunto: piano.

A informação sobre qual curso de graduação o documento está vinculado, Licenciatura em Música (Integral), é um dado do template do usuário. Nota-se que software Sophia usado pelo Sistema de Bibliotecas da UNIRIO mantém interoperabilidade com o padrão de metadados Dublin Core por meio do link http://biblioteca.sophia.com.br/ 5782/index.asp?codigo_sophia=94833, o que permitirá no futuro, com a digitalização das partituras, a criação de uma biblioteca digital.

Como vimos, na Figura 2, os dados descritivos têm seus campos nomeados de forma ajudar o usuário na identificação da obra. Na Figura 3 observamos os dados descritivos estruturados em MARC 21. Valendo-se dessa descrição podemos analisar o processo catalográfico. Os campos (000-008) trazem informações referentes ao controle de entrada do registro no sistema e envolve um conjunto de dados fixos, não repetíveis. No campo (008) encontramos a data de entrada do documento no sistema 25-03-2019. A partir do campo 090 a descrição centra-se nos dados variáveis, aqueles que são específicos de cada documento. No campo número de chamada (090), a partitura recebeu uma numeração interna (PAR 2489), que vem a ser também sua localização fixa. Como ponto de acesso principal foi definido o campo 100 (autor pessoa), sendo o nome do compositor normalizado sob a forma de cabeçalho (Guarnieri, M. Camargo) seguindo as orientações do capítulo 22 do AACR2r que versa sobre Cabeçalhos de Entrada para Nomes de Pessoas. No campo o título e responsabilidades (245) o título principal foi descrito conforme registrado na obra, sem alteração na grafia da palavra "dansa", seguindo as diretrizes do código de catalogação AACR2r, o mesmo ocorrendo com a descrição dos conteúdos das áreas de imprenta (260) e descrição física (300). 
Figura 3 - Descrição da partitura Dansa Brasileira no catálogo online do sistema de bibliotecas da UNIRIO - Interface formato MARC 21

Fonte: UNIRIO (2019)

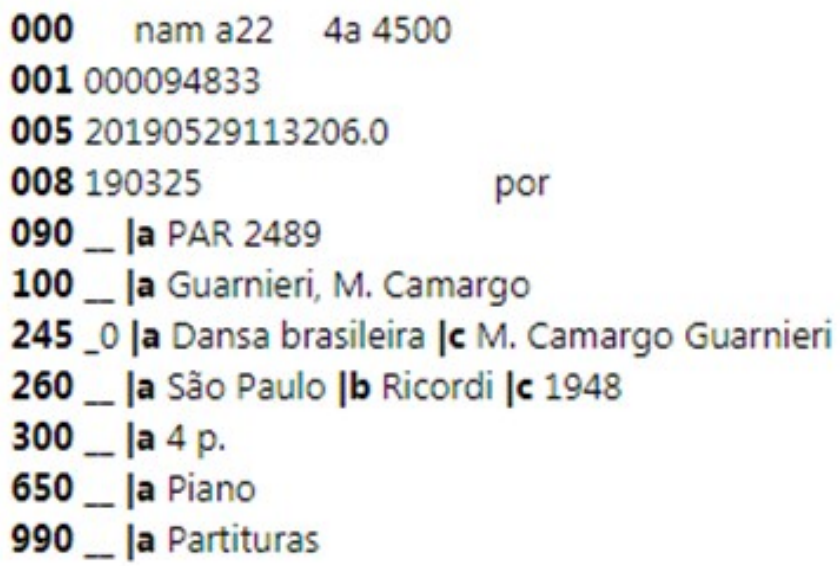

Observa-se no campo 245 que "indicador 1" ficou em branco o que nos informa que não foi gerada uma entrada secundária de título. Isso deve ter ocorrido porque o documento traz o titulo principal com a ortografia antiga, em que a palavra "dansa" aparece grafada com "s" - "dansa", o que exigiria a inclusão do campo 246 - titulo variante "dansa Brasileira". Esse recurso é utilizado pelo catalogador quando o título principal é diferente daquele registrado no campo 245, contribuindo, assim, para a identificação da obra pelo usuário. (MARANHÃO; MENDONÇA, 2017). Mas no caso da obra em análise, isso não foi feito.

Tematicamente a partitura foi representada pelo assunto "piano". A informação sobre qual curso de graduação atende a partitura, é um dado do template do usuário, sem correspondência com algum campo do MARC. Trata-se de uma informação que poderia ser descrita na área de notas gerais (campo 500). Mas isso também não foi feito.

Os campos 9XX e X9X são criados para permitir o registro de informações de interesse específico para os usuários e não são incluídos quando o registro bibliográfico é objeto de intercâmbio (OLIVEIRA et al., 2004). No caso da BSCLA, o campo 990 traz a informação Partituras, provavelmente relaciona-se ao tipo de coleção. Em situações de busca pode-se relacionar o assunto Piano ao termo Partituras por meio da booleana and (piano and partituras), o que permitirá o usuário encontrar uma variedade de documentos musicais referentes ao tipo documental "partitura para piano". 


\subsection{Discussão}

Analisando os elementos adotados na catalogação da partitura "Dansa Brasileira", constatamos que o uso do formato MARC 21 aumenta a eficiência no processo de recuperação da informação ao padronizar a catalogação, facilitando o intercâmbio de dados entre diferentes sistemas de informação.

Analisamos comparativamente os elementos usados na representação descritiva e temática nos catálogos da BSCLA com de outras instituições que possuem o mesmo documento - a partitura "Dansa Brasileira". Escolhemos três bibliotecas, a saber: a Biblioteca Nacional (BN) e a LC (Library of Congress), por serem entidades referência para a área de catalogação em âmbito nacional e internacional, respectivamente. No Quadro 3 apresentamos as descrições das bibliotecas mencionadas. Nessa comparação nos determos no conjunto de dados variáveis, aqueles que são específicos dos documentos e que padronizados auxiliam os usuários nos processos de busca e recuperação da informação.

Quadro 3 - Comparação entre as catalogações da Partitura Dansa Brasileira

\begin{tabular}{|c|c|c|c|}
\hline $\begin{array}{l}\text { CAMPOS DO } \\
\text { MARC } 21\end{array}$ & $\begin{array}{l}\text { CATALOGAÇÄOO } \\
\text { BSCLAVUNIRIO }\end{array}$ & CATALOGAÇÃO BN & CATALOGAÇÃO LC \\
\hline 040 Língua & |a por. & |a BR-RjBN |b por & |a IQU |b eng le rda \\
\hline $\begin{array}{c}\text { 080-084 } \\
\text { Classificação }\end{array}$ & $\begin{array}{l}\text { Classificação } \\
\text { alfa-numérica } \\
\text { |a PAR } 2489\end{array}$ & $\begin{array}{l}\text { Classificação CDD } \\
\text { |a M786.1 }\end{array}$ & Não aplicou \\
\hline $\begin{array}{l}050 \text { e } 090 \text { Número } \\
\text { de Chamada }\end{array}$ & $\begin{array}{l}\text { Localização fixa de } \\
\text { acordo com o número de } \\
\text { classificação }\end{array}$ & $\begin{array}{l}\text { Localização fixa } \\
\text { |a G-VII-14 }\end{array}$ & $\begin{array}{l}\text { Localização fixa } \\
\text { |a M25 |b.G }\end{array}$ \\
\hline $\begin{array}{c}100 \\
\text { Responsabilidade }\end{array}$ & $\begin{array}{l}\text { la Guarnieri, } \\
\text { M. Camargo }\end{array}$ & $\begin{array}{l}\text { |a Guarnieri, Camargo, Id } \\
\text { 1907-1993 }\end{array}$ & $\begin{array}{l}\text { |a Guarnieri, Camargo, } \\
\text { |d 1907-1993 }\end{array}$ \\
\hline $\begin{array}{l}245 \text { Titulo e } \\
\text { responsabilidade }\end{array}$ & $\begin{array}{l}\text { |a DansaBrasileira/ } \\
\text { |c M. Camargo Guarnieri } \\
\text { Indicador } \\
1 \text { - branco } \\
\text { Não gera entrada } \\
\text { adicional de título }\end{array}$ & $\begin{array}{l}\text { |a DansaBrasileira :|b } \\
\text { para piano } \\
\text { Indicador } 1-1 \\
\text { Indica entrada adicional } \\
\text { de título. }\end{array}$ & $\begin{array}{l}\text { |a Dansa Brasileira: } \\
\text { |b para piano / } \\
\text { |c M. Camargo Guarnieri } \\
\text { Indicador } 1-1 \\
\text { Indica entrada adicional } \\
\text { de título. }\end{array}$ \\
\hline $\begin{array}{c}\text { 260-264 } \\
\text { Publicação/Imprenta }\end{array}$ & $\begin{array}{l}\text { |a São Paulo :|bRicordi, } \\
\text { |c } 1948\end{array}$ & $\begin{array}{l}\text { |a [S. Paulo]: |b Ricordi } \\
\text { Brasileira, |c [c1947] }\end{array}$ & $\begin{array}{l}\text { |a [S. Paulo]: |b Ricordi } \\
\text { Brasileira, |c [c1947] } \\
\text { Indica que se trata de } \\
\text { uma reedição }\end{array}$ \\
\hline
\end{tabular}


Continuação

\begin{tabular}{|c|c|c|c|}
\hline $\begin{array}{l}\text { CAMPOS DO } \\
\text { MARC } 21\end{array}$ & $\begin{array}{l}\text { CATALOGACGÃO } \\
\text { BSCLA/UNIRIO }\end{array}$ & CATALOGAÇÃO BN & CATALOGAÇÃO LC \\
\hline $\begin{array}{c}\text { 300, 336, 337, } 338 \\
\text { Descrição física }\end{array}$ & la 4 p. & la $5 p$. & $\begin{array}{l}\mid \text { |a } 1 \text { score (4pages); } \\
\text { |c } 31 \mathrm{~cm} \\
\text { |a notated music |b ntm } \\
\text { |2 rda content } \\
\text { |a unmediated |b n } \\
\text { |2 rdamedia } \\
\text { |a volume |b nc |2 } \\
\text { rdacarrier } \\
\text { |a piano |n } 1 \text { |s } 1 \text { | } 2 \text { lcmpt }\end{array}$ \\
\hline 500 Notas & Não aplicou & |a Partitura & la For piano. \\
\hline 650 e 655 Assunto & la Piano & |a Música para piano & $\begin{array}{l}\text { |a Piano music. } \\
\text { la Dance music |z Brazil. } \\
\text { |a Art music. |2 lcgft } \\
\text { |a Dance music. |2 lcgft } \\
\text { |a Scores |2 lcgft }\end{array}$ \\
\hline $\begin{array}{l}990 \text { Informações } \\
\text { específicas da } \\
\text { Unidade de } \\
\text { Informação }\end{array}$ & |a Partitura & |a Partitura & Não aplicou \\
\hline
\end{tabular}

Fonte: elaborado pelos autores (2020)

Sobre a classificação usada nas instituições, enquanto que a biblioteca da UNIRIO criou uma classificação própria, formada pelas três letras iniciais da partitura e um número seqüencial (PAR 2489), a BN adotou a Classificação Decimal de Dewey (CDD) adicionando à notação a letra M (música) - M786.1. Já a LC não usou nenhum sistema para classificar o documento.

Sobre a localização, todas as bibliotecas adotam localização fixa. No caso da BSCLA,na classificação e na localização adota-se o mesmo código. Na entrada principal, a BN e LC adotam a forma normalizada dos cabeçalhos para o nome do autor, acrescido dos atributos data de nascimento e morte (Guarnieri, Camargo, 1907-1993). A BSCLA não adotou a forma normalizada, indicada pela BN e LC, optando em descrever o autor conforme as informações encontradas no documento (Guarnieri, M. Camargo). $\mathrm{Na}$ descrição do título principal as três bibliotecas mantiveram a grafia antiga da palavra "dansa", sendo que BN e LC acrescentaram o subtítulo "para piano", informação não apontada pela BSCLA. A LC e BN indicaram secundária para o titulo da obra, exceto a BSCLA, conforme já havíamos apontado quando analisamos os metadados descritivos da obra (ver Figura 3).

$\mathrm{Na}$ indicação da responsabilidade, tanto a Biblioteca da UNIRIO como a LC, descreveram as informações completas, exceto a BN. No campo Publicação/Imprenta 
há divergência sobre o ano de publicação da partitura. Outra divergência observada foi na descrição física no tocante ao número de páginas, enquanto BSCLA e LC indicam com 4 páginas, na BN a descrição informa 5 páginas.

A BN classificou o documento com o assunto "música para piano" e a BSCLA somente por "piano". Entendemos que o assunto atribuído pela BN é mais preciso, mas destacamos as relações temáticas feitas pelos catalogadores da LC indexando a obra em mais de um assunto, explorando facetas como: o recorte geográfico (Brasil), o instrumento (piano), as expressões música e dança, o tipo documental (partituras/scores). Essas são apenas algumas das relações obra/conteúdo, outras também poderiam ser feitas, caso tivéssemos um descrição mais exaustiva do recurso analisado - a partitura "Dansa Brasileira". Para uma descrição mais exaustiva, recomenda-se, com base em Cavalcanti e Carvalho (2011, p.144-147), a inclusão de outros atributos como: gênero musical; data de composição; tipologia da partitura; instrumentação; tonalidade principal; formato da partitura; coleção e série; e dados bibliográficos do autor. Nesse aspecto a descrição da LC, por estar alinhada com a norma RDA, traz uma variedade de atributos como forma do conteúdo e tipo de mídia, descritos nos campos 300, 336, 337 e 338.

O enriquecimento dos campos MARC 21 com entidades e atributos específicos dos documentos musicais exigirá do bibliotecário catalogador interlocução permanente com especialistas da área de música, pois são obras suscetíveis a reelaborações e reescritas que geram documentos derivados (outras expressões de uma mesma obra), que se manifestam em diferentes suportes papel, fitas de vídeo, recurso eletrônico, digitais etc.

\section{CONCLUSÃO}

A partir da presente pesquisa, foi possível estabelecer uma compreensão sobre o que é e como é formado um documento musical, como também a necessidade de conhecer as peculiaridades inerentes ao mesmo para um tratamento informacional que permita sua recuperação. Estudar a partitura a partir de Blanco (2016) permitiu estabelecer critérios para analisar um acervo musical, uma vez que suscitou reflexões sobre a necessidade do catalogador desenvolver competência informacional para tratar o documento musical e identificar suas especificidades. 
Como vimos, o documento musical caracterizado pelos elementos que compõem a música, como as notações, melodia, ritmo, harmonia, contraponto, altura, duração, intensidade e timbre, recomenda-se que o catalogador pesquise em fontes de informação reconhecidas na área musical, além de estabelecer um diálogo entre alunos e professores do curso de música, no âmbito de uma biblioteca universitária como a BSCLA, de forma a realizar um tratamento informacional mais fundamentado desse tipo de documento. Isso mostra a importância de o profissional da informação estar em um movimento de pesquisa e aprendizagem contínuo no intuito de conhecer as particularidades dos diferentes gêneros documentais depositados na biblioteca em que atua.

O uso de padrões, como a norma ISBD e o AACR2r, nos deram as diretrizes para identificação dos elementos essenciais que devem compor o registro documentário, sua ordem de citação, pontuação e forma de expressão do conteúdo. Dados informativos, bibliográficos e temáticos, que organizados de acordo com normas permitem identificar um documento musical de maneira unívoca com vista à sua recuperação e acesso. Como vimos, fazem parte desse conjunto a descrição bibliográfica, a definição de pontos de acessos (principal e secundário), o estabelecimento de cabeçalhos de autoria e de assunto, etc.

O uso do formato MARC 21 para a elaboração de catálogos eletrônicos facilita o trabalho descritivo, pois permite o uso e o reuso dos dados, mas sua aplicação exige conhecimento das normas de catalogação e dos processos de análise documentária e indexação, pois, um assunto, quanto mais especifico, garante maior precisão às buscas. No entanto, dependendo do público que queremos atingir podemos estender o elenco de termos ao fazermos a indexação.

No caso das bibliotecas universitárias, a política de catalogação tem que estar atenta às demandas do currículo, no caso dos cursos de música, às habilitações, ao desenvolvimento das disciplinas e às atividades de ensino, pesquisa e extensão. O catálogo deve ser estruturado para responder as perguntas de todos os usuários, docentes, discentes, artistas, cidadãos comuns, apreciadores e estudiosos de música. Conforme Mey e Silveira (2009), um catálogo deve a permitir a interseção entre as mensagens contidas nos documentos e as mensagens internas dos usuários [reais e potenciais] desse(s) acervo(s).

No que diz respeito ao intercâmbio de dados, seu uso exigirá adequação aos objetivos da biblioteca e às necessidades informacionais dos usuários, fazendo como que 
o catalogador, dependendo do contexto em que atue, elabore uma descrição mais exaustiva identificando outros atributos referentes ao(s) criador(es) e aos contextos de criação e produção de uma obra musical. Isso permitirá, por exemplo, que ao pesquisar sobre uma ópera, o catálogo mostre ao usuário todas as reelaborações e reescritas existentes para esta obra, tais como: partitura completa para orquestra, partes vocais, redução para canto e piano, etc., assim como, as pessoas e entidades que contribuíram para sua criação, produção e realização: compositores, orquestra, cantores, etc.

Assim sendo, concluímos ser de fundamental importância o catalogador estudar e pesquisar sobre as especificidades dos documentos musicais depositados nas bibliotecas em que atuam, de modo a realizar um tratamento informacional que possibilite ao usuário o acesso às suas diferentes expressões e manifestações, fazendo com que seu catálogo seja um instrumento de comunicação entre seu acervo e o público, que atenda aos propósitos da instituição e dos usuários proporcionando melhores resultados na recuperação do documento e da informação.

\section{REFERÊNCIAS}

ASSOCIAÇÃO BRASILEIRA DE NORMAS TÉCNICAS. NBR 6023: informação e documentação: referências: elaboração. 2 ed., Rio de Janeiro: ABNT, 2018.

ASSOCIAÇÃO BRASILEIRA DE NORMAS TÉCNICAS. NBR 12676: métodos para análise de documentos: determinação de seus assuntos e seleção de termos de indexação. Rio de Janeiro: ABNT, 1992.

ARQUIVO NACIONAL (Brasil). Dicionário brasileiro de terminologia arquivística. Rio de Janeiro: Arquivo Nacional, 2005. Disponível em: http://www.arquivonacional.gov.br/images/pdf/Dicion_Term_Arquiv.pdf. Acesso em 2 out. 2018.

BARBOSA, A. P. Teoria e prática dos sistemas de classificação bibliográfica. Rio de Janeiro: Instituto Brasileiro de Bibliografia e Documentação, 1969. 441 p. Disponível em: http://livroaberto.ibict.br/handle/1/100. Acesso em 10 jan. 2020.

BARROS, C. M. Representação da Informação Musical: Subsídios para recuperação da informação em registros sonoros e partituras no contexto educacional e de pesquisa. 2012. $150 \mathrm{f}$. Dissertação (mestrado em ciência da informação) - Universidade Federal de Santa Catarina, Centro de Ciências da Educação, Florianópolis, Santa Catarina, 2012. Disponível em:

https://repositorio.ufsc.br/bitstream/handle/123456789/96442/301788.pdf?sequence=1\&isAllowed=y. Acesso em: 2 out. 2018.

BLANCO, P. S. Documentação Musical e musicográfica: Em prol de uma terminologia necessária. In: BLANCO, P. S.; SIQUEIRA, M. N.; VIEIRA, T. O. (Org). Ampliando a discussão em torno de documentos audiovisuais, iconográficos, sonoros e musicais. Salvador: EDUFBA, 2016. p. 73-116. Disponível em: http://repositorio.ufba.br/ri/handle/ri/20828. Acesso em 6 ago. 2020. CARDOSO, I. V. Vocabulário controlado para indexação de partituras de música brasileira: proposta por uma estrutura básica. Transinformação, n. 3, v. 8, 1996. Disponível em: http://periodicos.puc-campinas.edu.br/seer/index.php/transinfo/article/view/1603/1575. Acesso em: 18 mai. 2018. 
CAVALCANTI, C. H.; CARVALHO, M. A. A informação na música impressa: Elementos para análise documental e representação de conteúdos. Revista Digital de Biblioteconomia e Ciência da Informação, Campinas, v. 8, n. 2, p. 132-151, jan. /jun. 2011. Disponível em: https://periodicos.sbu.unicamp.br/ojs/index.php/rdbci/article/view/1937. Acesso em: 10 out. 2018.

CÓDIGO de catalogação anglo-americano: [edição revista 2002]. Tradução para língua portuguesa sob a responsabilidade da FEBAB. São Paulo: Imprensa Oficial/FEBAB, 2004.

CRUZ, M. B. Necessidades de informação musical para usuários não especializados. 2008. 311 f. Tese (Doutorado em Ciência da Informação) - Universidade de Brasília, Departamento de Ciência da Informação e Documentação, Brasília, DF. 2008. Disponível em: https://repositorio.unb.br/bitstream/10482/3987/1/2008_FernandoWilliamCruz.pdf. Acesso em: 28 out. 2018.

CUNHA, M. B.; CAVALCANTI, C. R. O. Dicionário de biblioteconomia e arquivologia. Brasília, DF: Briquet de Lemos, 2008.

DIAS, E. W.; NAVES, M. M. L. Análise de assunto: teoria e prática. 2. ed. rev. Brasília, DF: Briquet de Lemos, 2013.

FUJITA, M. S. L. ; RUBI, M. P. Um modelo de leitura documentária para a indexação de artigos científicos: princípios de elaboração e uso para a formação de indexadores. Data Grama Zero, Rio de Janeiro, v. 7, n. 3, 2006. Disponível em: https://brapci.inf.br/index.php/res/v/5926. Acesso em: 6 ago 2020.

GUARNIERI, M. C. Dansa Brasileira. São Paulo: Ricordi, 1948.

IFLA - International Federation of Library Associations and Institutions. ISBD International Standard Bibliographic Description. Consolidated edition. München: IFLA; K.G. Saur, 2011. Disponível em: https://www.ifla.org/files/assets/cataloguing/isbd/isbd-cons_20110321.pdf Acesso em: 16 out 2020

LANCASTER, F. W. Indexação e resumos: teoria e prática. 2. ed. rev. e atual. Brasília, DF: Briquet de Lemos, 2004, 452p.

MATOS, A. L. H. Documentação musical: Discussão sobre a representação temática de partituras a partir de um enfoque interdisciplinar. 2007. 104 f. Dissertação (mestrado em ciência da informação) - Universidade de São Paulo, Escola de Comunicação e Artes, São Paulo, 2007. Disponível em: https://teses.usp.br/teses/disponiveis/27/27151/tde-05072009190855/publico/103252.pdf. Acesso em: 2 out. 2018.

MARANHÃO, A. M. N.; MENDONÇA, M. L. S. MARC 21: formato bibliográfico. Rio de Janeiro: PUC/RJ, 2017.

MEY, E. S. A.; SILVEIRA, N. C. Catalogação no plural. Brasília, DF: Briquet de Lemos, 2009. SADIE, S. Dicionário Grove de música: edição concisa. Rio de Janeiro: Zahar, 1994.

OLIVEIRA, Z.P. et al. O uso do campo MARC 9XX para controle bibliográfico institucional. Revista Ciência da Informação, Brasília, DF, v. 33, n. 2, p. 179-186, maio/ago. 2004. Disponível em: https://www.scielo.br/pdf/ci/v33n2/a19v33n2.pdf Aceso 16 out. 2020

SERRA, L. et al. Os princípios de descrição e sua aderência aos formatos MARC 21 e ONIX. Revista Ciência da Informação, Brasília, DF, v. 46 n. 2, p. 51-66, maio/ago. 2017. Disponível em: http://revista.ibict.br/ciinf/article/viewFile/2327/3699. Acesso 15 ago 2020

SILVEIRA, N. C. Um diálogo sobre instrumentos de representação descritiva In: ZAFALON Z. R.; DAL'EVEDOVE, P. R. (org.).Perspectivas da representação documental: discussão e experiências.São Carlos: CPOI/UFSCar, 2017. p. 177-191.

SOUZA, R. L. L. Microtesauro em música: teoria e prática. 2008. 564 f. Monografia (Bacharelado em Biblioteconomia) - Universidade de Brasília, Brasília, 2008. Disponível em https://bdm.unb.br/bitstream/10483/1219/1/2008_Rom\%c3\%a9lioLemosSouza.pdf. Acesso em 7 mai. 2019 
UNIRIO. Catálogo dos sistemas de biblioteca: Sophia on-line. Disponível: http://biblioteca.sophia.com.br/5782/. Acesso: 22 jun. 2019.

UNISIST. Princípios de indexação. Revista da Escola de Biblioteconomia da UFMG, Belo Horizonte, v. 1, p. 83-94, mar. 1981. Disponível em: https://brapci.inf.br/index.php/res/v/73723. Acesso em 7 mai. 2019. 